\title{
Application of cosmic-ray neutron sensing to monitor soil water content in an alpine meadow ecosystem on the northern Tibetan Plateau
}

\author{
Xuchao Zhu ${ }^{\mathrm{a}, \mathrm{b}}$, Ming'an Shao ${ }^{\mathrm{a}, \mathrm{d}, *}$, Chen Zeng ${ }^{\mathrm{c}}$, Xiaoxu Jia ${ }^{\mathrm{a}}$, Laiming Huang ${ }^{\mathrm{a}}$, Yangjian Zhang ${ }^{\mathrm{a}}$, \\ Juntao Zhu ${ }^{\text {a }}$ \\ ${ }^{a}$ Key Laboratory of Ecosystem Network Observation and Modeling, Institute of Geographic Sciences and Natural Resources Research, Chinese Academy of Sciences, \\ Beijing 100101, China \\ ${ }^{\mathrm{b}}$ University of Chinese Academy of Sciences, Beijing 100049, China \\ ${ }^{\mathrm{c}}$ Key Laboratory of Tibetan Environment Changes and Land Surface Processes, Institute of Tibetan Plateau Research, Chinese Academy of Sciences, Beijing 100101, China \\ ${ }^{\mathrm{d}}$ State Key Laboratory of Soil Erosion and Dryland Farming on the Loess Plateau, Northwest AEF University, Yangling 712100, China
}

\section{A R T I C L E I N F O}

\section{Article history:}

Received 6 December 2015

Received in revised form 16 February 2016

Accepted 20 February 2016

Available online 3 March 2016

This manuscript was handled by Corrado Corradini, Editor-in-Chief, with the assistance of Juan V. Giraldez, Associate Editor

\section{Keywords:}

CRNS

Soil moisture

Alpine meadow

Tibetan Plateau

\begin{abstract}
S U M M A R Y
Cosmic-ray neutron sensing (CRNS) is a new method for continuously monitoring mean soil water content (SWC) on a hectometer scale. To evaluate the application and accuracy of the method for SWC observation in an alpine meadow ecosystem (AME), we installed the CRNS in a flat meadow near the Naqu prefecture on the northern Tibetan Plateau. We collecting soil samples and applying the system by the oven-drying method. A weather station was also installed near the CRNS for monitoring basic meteorological variables and the soil temperature and water content at various depths. Three Em-50 instruments for monitoring SWC and soil temperature were buried in three sub-quadrats northwest, northeast and southeast of the CRNS at distances of 460,370 and $373 \mathrm{~m}$, respectively, to observe the variation of SWC at the various depths. The footprint of the CRNS for SWC observation in the meadow was about $580 \mathrm{~m}$, and the mean measuring depth was about $31 \mathrm{~cm}$ according to the general calculation equations. The reference neutron flux for dry soil $\left(N_{0}\right)$ had a mean and coefficient of variation of 8686 and $3 \%$, respectively, and remained substantially invariant throughout the measuring period. The five SWCs from the independent field samples almost passed through the SWC trend of the CRNS, the root mean square error (RMSE) was $0.011 \mathrm{~m}^{3} \mathrm{~m}^{-3}$ for the CRNS and oven-drying method. The time series of SWC measured by the CRNS agreed well with the mean SWC series to a depth of $20 \mathrm{~cm}$ measured by the weather station. The trend of SWC measured by the Em-50s generally agreed with the trend of SWC measured by the CRNS, but some values and variations of SWC differed between the Em-50s and CRNS data. Because of the good agreement between the CRNS and independent field samples, we suspect that this disagreement is due to an insufficient representativeness of point observations and the distances of the points from the CRNS. The diurnal variation of hourly SWC from the CRNS was sinusoidal during a dry period, peaking at 11:00 and was minimum at 18:00 (Beijing time), with a range of $1 \%$. Overall, the CRNS measured SWC in the AME with an acceptable accuracy, providing a scientific basis for the promotion and application of the CRNS in high, cold ecosystems.
\end{abstract}

(c) 2016 Elsevier B.V. All rights reserved.

\section{Introduction}

Soil moisture is an important component of Earth's water and sustains the existence and multiplication of surface life and the stable development of land-surface ecological systems. Soil moisture controls regional hydrometeorology by assigning rainfall

\footnotetext{
* Corresponding author at: Key Laboratory of Ecosystem Network Observation and Modeling, Institute of Geographic Sciences and Natural Resources Research, Chinese Academy of Sciences, Beijing 100101, China.

E-mail address: shaoma@igsnrr.ac.cn (M. Shao).
}

into infiltration and runoff and controls the exchange of energy between the land surface and the atmosphere by evaporation (Jia and Shao, 2013). Accurate observation of soil water content (SWC) could improve the accuracy of weather and climate forecasting, prevent a variety of weather-related disasters and improve the management efficiency of agricultural water (Rosolem et al., 2014).

SWC can be monitored by many methods, such as oven drying, neutron probes, time domain reflectometry and frequency domain reflectometry (Vereecken et al., 2014). All these are point measuring methods, the measuring scale is small and the 
representativeness is insufficient in space. Remote sensing methods, however, can invert SWC at large scales at shallow inversion depths and would be influenced by topography and vegetation. Cosmic-ray neutron sensing (CRNS) is a newly developed method for measuring SWC that is being rapidly adopted due to its unique advantages of automatic and nondestructive observation. Cosmicrays are common and enter the atmosphere after penetrating Earth's magnetic field. Primary cosmic-rays interact with atmospheric nuclei and produce fast neutrons. The fast neutrons can then enter the soil and be moderated by hydrogen atoms, the main source of which is soil water, and the moderated neutrons can then be counted by the cosmic-ray probe located near ground level (Zreda et al., 2012). Hydrogen atoms are severalfold more efficient than the next most efficient element, carbon, at moderating fast neutrons. The intensity of neutrons is inversely proportional to SWC, which is the major operating principle of the CRNS. Unlike the conventional methods of measuring SWC, the CRNS can continuously measure the mean SWC of what can be conceived to be a flat-topped cylinder of soil. The radius of the horizontal footprint of the CRNS, the region containing $86 \%$ of the detected neutrons, is estimated to be about $300 \mathrm{~m}$ by Desilets and Zreda (2013) and from 130 to $240 \mathrm{~m}$ by Köhli et al. (2015) at sea level (atmospheric pressure of $1013 \mathrm{hPa}$ ). The surveying depth is estimated to be about $12 \mathrm{~cm}$ (saturated soil) to $76 \mathrm{~cm}$ (dry soil) by Zreda et al. (2008) and from 15 to $83 \mathrm{~cm}$ by Köhli et al. (2015). A hectometer scale can compensate the deficiency of soil moisture observation between point and remote sensing images.

The CRNS has been widely studied in recent years. Several methods are available to estimate SWC from the measured neutron intensity. The $N_{0}$-method (Desilets et al., 2010), the hydrogen molar fraction method (Franz et al., 2013) and the COSMIC operator method (Shuttleworth et al., 2013) were calibrated by the Monte Carlo Neutron-Particle eXtended (MCNPX) radiation transport code. Baatz et al. (2014) compared the three methods and found that they all performed similarly well during validation. The $N_{0}$ method is the simplest for estimating SWC because it requires only one parameter. Desilets et al. (2010) obtained the generalized SWC calibration equation by fitting the neutron flux obtained from the MCNPX radiation transport code and reported the values of the parameters in the equation. Franz et al. (2012) derived an equation for calculating the depth of SWC measurements. Desilets and Zreda (2013) used diffusion theory and the neutron-transport model to derive an equation for estimating the footprint radius and analyzed the factors influencing the radius. Zreda et al. (2012) systematically explained the principle, calculations, influencing factors, calibration and application of the CRNS to provide a better understanding for the wider application of this new approach. The correction of influencing factors has also received much attention. The analysis and correction of the influences of atmospheric pressure, water vapor, solar activity and aboveground biomass on the neutrons have been studied (Desilets and Zreda, 2001; Moraal et al., 2005; Rosolem et al., 2013; Coopersmith et al., 2014; McJannet et al., 2014; Baatz et al., 2015) and can improve the accuracy of the CRNS. These studies have built the foundation for the application of the CRNS method (Rivera villarreyes et al., 2011; Bogena et al., 2013; Han et al., 2014; Wang et al., 2015).

The CRNS has a solid theoretical and growing empirical foundation (Zreda et al., 2012) and has been applied in a variety of ecosystems, such as forest (Lv et al., 2014), farmland (Zhu et al., 2015) and grassland (Zhao et al., 2015), under different climatic conditions. CRNS networks have been installed in the USA (Zreda et al., 2012), Australia (Hawdon et al., 2014), Germany (Baatz et al., 2014), Africa and England (Rosolem et al., 2014). The performance of the CRNS, however, remains uncertain for degraded ecosystems with extreme climatic conditions due to the impact of vegetation, soil properties and altitude. The purpose of this study was thus to evaluate the accuracy and application of the CRNS in an alpine meadow ecosystem (AME) of the northern Tibetan Plateau and to provide a reference and scientific basis for its application in other AMEs.

\section{Materials and methods}

\subsection{Site description}

This experiment was carried out at the Station of Grassland Ecosystem Research on the Northern Tibetan Plateau of the Institute of Geographic Sciences and Natural Resources Research, Chinese Academy of Sciences $\left(31.64^{\circ} \mathrm{N}, 92.01^{\circ} \mathrm{E}\right)$, on the northern Tibetan Plateau, $19 \mathrm{~km}$ northwest of Naqu Prefecture (Fig. 1). The average elevation is ca. $4600 \mathrm{~m}$ above sea level, but the relative elevation is less than $10 \mathrm{~m}$ in the study plot. The study area has a sub-frigid and semi-humid monsoon climate with a cold and long winter. The growing season is from June to August, and the soil is frozen for the rest of the year. The mean temperature in 2014 was $0.6^{\circ} \mathrm{C}$, with a minimum of $-18.8^{\circ} \mathrm{C}$ on 18 December and a maximum of $13.2{ }^{\circ} \mathrm{C}$ on 25 June. The total precipitation was $592.1 \mathrm{~mm}$, with $510.4 \mathrm{~mm}$ (86.2\%) falling from June to September. Mild hailstorms occurred occasionally in the early and late stages of the 2015 growing season, but the hailstones melted immediately after the sun appeared. The mean relative humidity was only $48 \%$. The mean atmospheric pressure is $587 \mathrm{hPa}$, which is only $58 \%$ of the pressure at sea level. The climate in the study area is generally cold, dry and windy. The soil is an alpine meadow soil, a sandy loam, with a high sand content (Table 1), indicating a small amount of lattice water. Stones are distributed sporadically in the top $30 \mathrm{~cm}$ of soil and extensively below $30 \mathrm{~cm}$, which impedes the sampling. The zonal vegetation is alpine meadow dominated by Kobresia pygmaea associated with Potentilla spp., Leontopodium pusillum and Carex moorcroftii, all of which are annual herbs. The mean total above ground biomass was low and estimated to be 78, 51 and $93 \mathrm{~g} \mathrm{~m}^{-2}$ on 9 July, 27 July and 24 August, respectively.

An irregular polygonal fence was built on a relatively flat meadow beside the research station in 2011 to prevent cattle grazing and to act as the boundary of the sample plot, which was ca. $480 \mathrm{~m}$ wide from the southwest to the northeast and ca. $700 \mathrm{~m}$ long from the southeast to northwest, for a total area of ca. 33.6 ha. Sub-quadrats of $20 \times 20 \mathrm{~m}$ were established in the northwest, northeast and southeast edges of the plot in 2011, 2012 and 2013, respectively (Fig. 1), for observing the impacts of different durations of grazing prohibition on the SWC and soil temperature in various layers. The distances from the 2011, 2012 and 2013 subquadrats to the center of the sample plot were 467, 370 and $373 \mathrm{~m}$, respectively.

\subsection{Instrumentation and measurement}

\subsubsection{The cosmic-ray soil moisture observing system}

The cosmic-ray soil moisture observing system was installed in the middle of the sample plot (Fig. 1). Its main component is a moderated fast-neutron probe, which was filled with $\mathrm{He}-3$ instead of conventional boron trifluoride, and was produced by Probe Science and Technology Ltd., Beijing, China. The probe was fixed $50 \mathrm{~cm}$ above the ground on a steel tube by iron wire. The system also included a data-acquisition system and a solar panel. The data acquisition system consisted of a data logger, a battery and a solarcharge controller. The battery provided the power to the system and maintained a relatively constant voltage of $12 \mathrm{~V}$. A temperature sensor was installed on the solar-charge controller to measure the air temperature in the box. The cosmic-ray soil moisture 


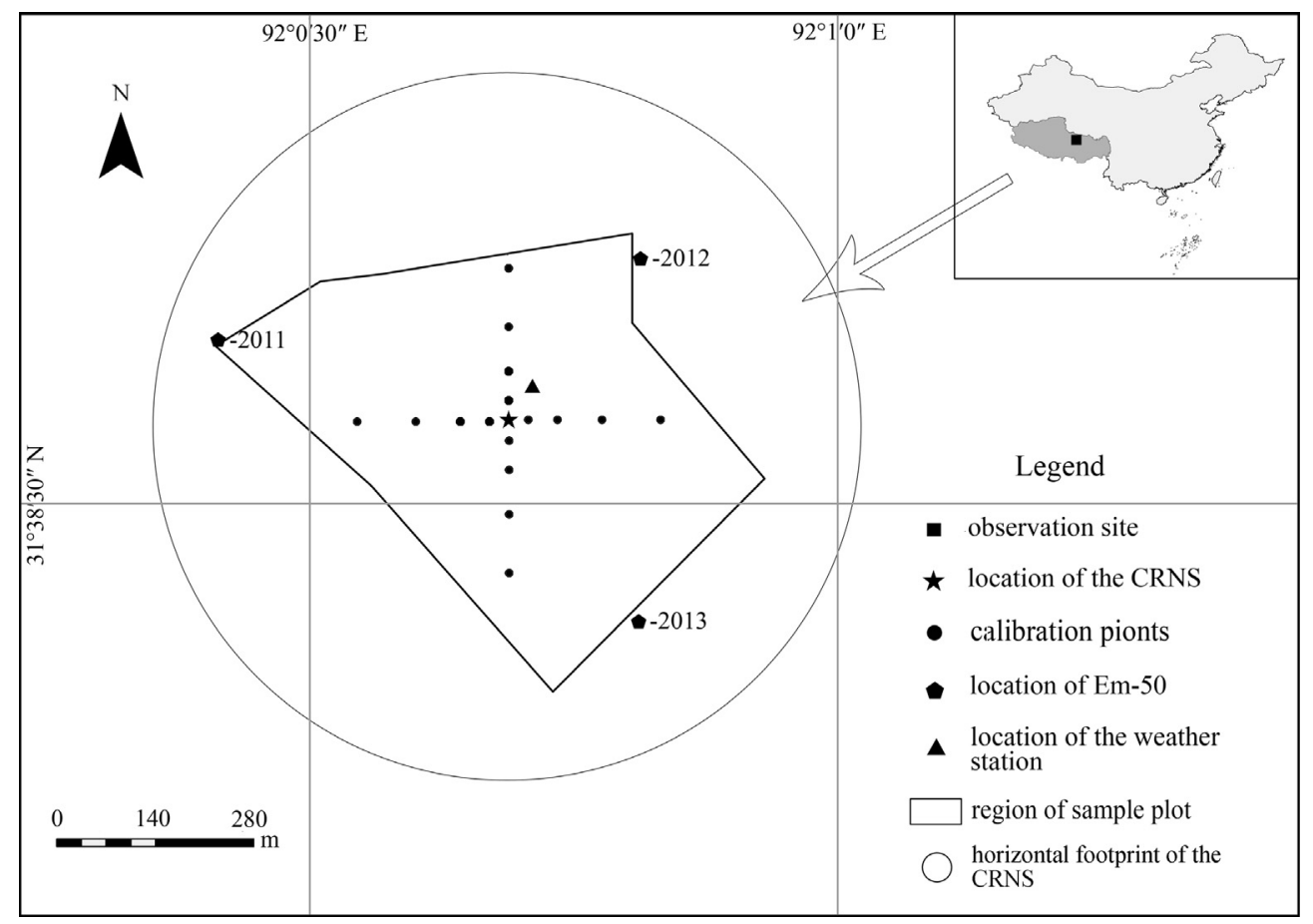

Fig. 1. Location of the observation site and the experimental sampling design.

Table 1

Soil particle-size composition in various layers of the sampling area.

\begin{tabular}{llll}
\hline Layer $(\mathrm{cm})$ & Clay content $(\%)$ & Silt content $(\%)$ & Sand content $(\%)$ \\
\hline $0-10$ & 17.8 & 16.2 & 66.1 \\
$10-20$ & 14.6 & 13.3 & 72.1 \\
$20-30$ & 17.0 & 13.4 & 69.6 \\
$30-40$ & 17.6 & 13.0 & 69.3 \\
$40-50$ & 17.3 & 12.5 & 70.1 \\
\hline
\end{tabular}

observing system became operational on 20 May, 2015, and the time interval for data collection was set to $1 \mathrm{~h}$. We analyzed the data from 15 June to 6 September 2015, which included most of the growing season.

\subsubsection{Soil samples}

Calibration points $25,75,150$ and $250 \mathrm{~m}$ east, west, south and north of the CRNS (Fig. 1) were marked with a white wooden stick. Disturbed soil samples were collected at depths of 10, 20 and $30 \mathrm{~cm}$ using small aluminum boxes by the soil drill method, and undisturbed soil core samples $\left(100 \mathrm{~cm}^{3}\right)$ were collected by digging a soil pit to a depth of $30 \mathrm{~cm}$ at each point. Forty-eight samples were thus collected in each campaign from which the mean SWC for the area could be computed. This process was performed on 9 July, 17 July, 27 July, 16 August and 24 August 2015. The mean volumetric SWC was computed by assigning weights which diminished exponentially with depth and the distance from the CRNS to the samples. The data of the mean volumetric SWC was then used to compare with the SWC measured by the CRNS.

\subsubsection{Em-50 instruments}

An Em-50, equipped with five TM probes (Decagon Devices, Inc., Washington, USA), is an instrument for measuring SWC by measuring the dielectric constant of the soil using frequency domain technology. An Em-50 was buried in each of the three sub-quadrats at the edge of the sample plot (Fig. 1) on 5 July 2015 to monitor SWC and temperature at various soil depths. The probes of the Em-50 in the 2011 and 2012 sub-quadrats were set at depths of 5, 10, 20, 40 and $60 \mathrm{~cm}$. Two of the probes of the Em-50 in the 2013 subquadrat were damaged, so data were collected by this instrument from only three depths of 5,10 and $20 \mathrm{~cm}$. The data collection interval was set to $1 \mathrm{~h}$ for keeping consistent with the cosmic-ray neutron method. We used the vertical mean SWCs calculated from three depths of 5, 10 and $20 \mathrm{~cm}$ from each Em-50 from 5 July to 7 September to compare with the SWCs measured by the CRNS.

\subsubsection{Meteorological data}

A weather station was installed about 190 m northeast of the CRNS (Fig. 1) to monitor air temperature, relative humidity, atmospheric pressure, rainfall, solar radiation and SWC and soil temperature at depth of 5, 10, 20 and $50 \mathrm{~cm}$. We used air temperature, vapor density and atmospheric pressure to correct the raw neutron intensity and mean SWC data at depths of 5, 10 and $20 \mathrm{~cm}$ to compare with the SWCs measured by the CRNS.

\subsection{Horizontal and vertical footprints of the CRNS}

The SWC measured by the CRNS is a mean value for what can be conceived to be a flat-topped cylinder of soil. MCNPX simulations indicate that the radius $(R)$ of the horizontal footprint at sea level (air pressure of $1013 \mathrm{hPa}$ ) is about $300 \mathrm{~m}$ and is mainly affected by the properties of the atmosphere and has little relationship with SWC (Desilets and Zreda, 2013). In a newer study, however, the radius was between 130 and $240 \mathrm{~m}$, and a calculation equation was proposed (Köhli et al., 2015). According to Desilets and Zreda (2013), $R$ could be calculated using the equation:

$R=R_{0}\left(\frac{P_{0}}{P}\right)$

where $R(\mathrm{~m})$ is the footprint radius at air pressure $P(\mathrm{hPa})$, and $R_{0}$ is the reference radius $\left(300 \mathrm{~m}\right.$ ) at the reference air pressure $P_{0}$ (a standard air pressure at sea level, $1013 \mathrm{hPa}$ ) (Zreda et al., 2008).

The depth $z(\mathrm{~cm})$ was defined as the depth at which $86 \%$ of the neutrons are detected, is negatively correlated with SWC and depends little on other soil properties (Franz et al., 2012). Hydrogen atoms have the highest efficiency for moderating the fast 
neutrons that enter the soil. More water in the soil will thus slow more fast neutrons, and fewer fast neutrons will reach deeper soil, so $z$ will be shallower (Franz et al., 2012). The depth $z$ was calculated as:

$z=\frac{5.8}{\rho_{b d} \tau+\theta+0.0829}$

where $\rho_{b d}$ is the soil bulk density $\left(\mathrm{g} \mathrm{cm}^{-3}\right), \tau$ is the lattice water content $\left(\mathrm{g} \mathrm{g}^{-1}\right)$, and $\theta$ is the soil volumetric water content $\left(\mathrm{cm}^{3} \mathrm{~cm}^{-3}\right)$. The amount of lattice water is small compared with SWC and can be ignored in the calculation in our study.

\subsection{Correction and calibration}

The CRNS can monitor the mean SWC over a long time sequence. Because SWC and soil temperature, air pressure and other factors vary over time, the raw neutron intensity should thus be corrected before SWC is calibrated. Fluctuations in atmospheric pressure, water vapor and solar activity are the main factors that affect the neutron intensity (Rosolem et al., 2013; Zreda et al., 2012).

Air pressure varies over time and space. Higher air pressure increases the number of collisions between cosmic-rays and atmospheric molecules thereby fewer fast neutrons can reach the ground. More moderated fast neutrons can thus be detected under the same conditions of soil moisture when barometric pressure is lower. The formula to correct for variation of air pressure in latitude and altitude is (Desilets and Zreda, 2001):

$N_{p}=N_{\text {raw }} \exp \left(\frac{P_{0}-P}{L}\right)$

where $N_{\text {raw }}$ is the original density of the moderated fast neutrons, $N_{p}$ is the neutron intensity after the correction for air pressure and $L$ is the mass attenuation length for high-energy neutrons $\left(\mathrm{g} \mathrm{cm}^{-2}\right)$ that varies between $128 \mathrm{~g} \mathrm{~cm}^{-2}$ (at high latitudes) and $142 \mathrm{~g} \mathrm{~cm}^{-2}$ (near the equator) (Zreda et al., 2012). The value of $L$ at our study site was ca. $137 \mathrm{~g} \mathrm{~cm}^{-2}$.

Hydrogen atoms moderate fast neutrons most efficiently, and the number of moderated neutrons detected and the hydrogen atom content (i.e. the water content) of soil are negatively correlated, which is the principle and basis of the CRNS. Atmospheric water-vapor content varies with meteorological elements such as air temperature and wind speed, so the number of hydrogen atoms in the water vapor will affect the accuracy of the results of the CRNS. The correction formula is (Rosolem et al., 2013):

$N_{p w}=N_{p}\left(1+0.0054\left(\rho-\rho_{0}\right)\right)$

where $N_{p w}$ is the neutron flux corrected by water vapor and air pressure, $\rho$ is the absolute vapor density $\left(\mathrm{g} \mathrm{m}^{-3}\right)$ and $\rho_{0}$ is the vapor density under reference conditions (generally set to $0 \mathrm{~g} \mathrm{~m}^{-3}$ ).

Solar activity can significantly influence the intensity of incoming neutrons on a timescale of months and even occasionally on a timescale of a few days, so the fluctuations in the incoming neutron intensity accordingly need to be removed. The intensity correction factor, $f_{i}$, can be expressed as (Han et al., 2015):

$f_{i}=\frac{N_{m}}{N_{a}}$

where $N_{m}$ is the measured neutron monitor intensity at a given time and $N_{a}$ is the average neutron intensity during the measurement period. The measured neutron data are from Jungfraujoch, Switzerland.

The final equation is thus:

$N=N_{\text {raw }}\left(\exp \left(\frac{P_{0}-P}{L}\right)\right) \cdot\left(1+0.0054\left(\rho-\rho_{0}\right)\right) / f_{i}$ where $N$ is the neutron flux after correction for water vapor, air pressure and solar activity.

The corrected neutron flux is negatively and nonlinearly proportional to SWC. The shape-defining function developed by Desilets et al. (2010) was widely used to determine $\theta\left(\mathrm{m}^{3} \mathrm{~m}^{-3}\right)$ (Desilets et al., 2010):

$\theta(N)=\frac{a_{0}}{\left(\frac{N}{N_{0}}\right)-a_{1}}-a_{2}$

where $N$ is the corrected neutron flux, $N_{0}$ is the neutron flux in dry soil under the same reference condition (obtained from the measured SWCs in the footprint) and parameters $a_{0}=0.0808$, $a_{1}=0.372, a_{2}=0.115$ are dimensionless. All five mean volumetric SWCs in this study were used for calculating the values of $N_{0}$, and the mean value of $N_{0}$ was used for calibration. The five samples were then used for evaluation.

\section{Results}

\subsection{Field SWC sampling and calculating $N_{O}$}

The mean SWCs for the 16 points at different depths are presented in Table 2. The SWC at the three depths was low in July and increased in August. SWCs at the three depths all first decreased and then increased with time, due to an abnormal drought in July, which may have been caused by the impact of the El Nino in 2015. The order of the ranges of SWC at the three depths was $10>20>30 \mathrm{~cm}$, i.e. the amplitude degree of the SWC decreased with depth.

Table 3 shows the statistical features for $N_{0}$, bulk density (BD) and the field mean SWC. The mean values and the ranges for $N_{0}$, BD and SWC were 8686 and 650 count h$^{-1}, 1.2$ and $0.95 \mathrm{~g} \mathrm{~cm}^{-3}$ and 11.5 and $8.6 \%$, respectively. The variation amplitude and coefficient of variation were 7.8 and 3.0\%, respectively, for $N_{0}$ and 129.9 and $26.1 \%$, respectively, for SWC. The statistical data for $N_{0}$ indicated that $N_{0}$ did not vary with time, so it could be thought that there is no systematic bias in the calibration function over the range of moisture values sampled and for the conditions of this site. We thus deemed one calibration for $N_{0}$ to be sufficient during the 2015 growing season.

\subsection{Footprint radius and measuring depth}

The horizontal footprint radius and the measuring depth were calculated using the general Eqs. (1) and (2).

Fig. 2 showed the variation of the radius, air pressure, air temperature and topsoil temperature over time. The radius fluctuated irregularly during the growing season, as did the air pressure, but they fluctuated oppositely at any one time (Fig. 2, Eq. (1)). The mean radius was $580 \mathrm{~m}$, with a maximum of $588 \mathrm{~m}$ and a minimum of $575 \mathrm{~m}$. The standard deviation of the radius was very small and the variable coefficient was only $0.3 \%$. It thus could be thought as a constant in a relatively long period. The radius in this alpine meadow at $4600 \mathrm{~m}$ was estimated to be $580 \mathrm{~m}$, which is $75.8 \%$ larger than the radius at sea level. The radius present in this study is much larger than in most of other studies (Zhao et al., 2015; Zhu

Table 2

Field mean SWC (Vol. \%) at depths of 10, 20 and $30 \mathrm{~cm}$ for the five campaigns.

\begin{tabular}{rlrlll}
\hline & 9 July & 17 July & 27 July & 16 August & 24 August \\
\hline 10 & 12.9 & 8.7 & 5.4 & 20.7 & 18.5 \\
20 & 11.6 & 10.1 & 6.3 & 12.6 & 14.0 \\
30 & 11.6 & 11.0 & 8.3 & 7.7 & 13.3 \\
\hline
\end{tabular}


Table 3

Statistical features for $N_{0}$ (counts $\mathrm{h}^{-1}$ ), bulk density $\left(\mathrm{BD}, \mathrm{g} \mathrm{cm}^{-3}\right.$ ) and field mean SWC (Vol. \%).

\begin{tabular}{lllllc}
\hline & Minimum & Maximum & Mean & $\begin{array}{l}\text { Standard } \\
\text { deviation }\end{array}$ & $\begin{array}{c}\text { Coefficient of } \\
\text { variation }(\%)\end{array}$ \\
\hline$N_{0}$ & 8343 & 8993 & 8686 & 263 & 3.0 \\
BD & 0.63 & 1.58 & 1.20 & 0.26 & 21.5 \\
SWC & 6.7 & 15.3 & 11.5 & 3.4 & 26.1 \\
\hline
\end{tabular}

et al., 2015) mainly due to the very high altitude (Desilets and Zreda, 2013; Eq. (1)).

The measuring depth of the CRNS was closely but negatively associated with SWC neutrons counts (Fig. 3, Eqs. (2) and (7)). Precipitation occurred relatively uniform in late June and early July, which produced relatively stable levels of soil water and thus measuring depth at about $30 \mathrm{~cm}$. An abnormal drought with almost no rain occurred from mid- to late July, neutrons counts increased continuously and the measuring depth increased accordingly (curve in the dashed box in Fig. 3). Rain was recorded from early August to early September, and the mean intensity was higher than that in June and July, which contributed to the lower neutrons counts, and the measuring depth remained near $24 \mathrm{~cm}$. The relationship between measuring depth and rainfall indicated that the SWC neutrons counts was sensitive to rainfall in this meadow system. Rainfall in the study area had generally been relatively uniform during the growing seasons of other years, but the impact of an El Nino in 2015 led to the abnormal drought from mid- to late July, which decreased SWC and increased measuring depth. The measuring depth of the CRNS during the 2015 growing season ranged from 20 to $50 \mathrm{~cm}$, with a mean of $31 \mathrm{~cm}$.

\subsection{Comparison of SWCs from the CRNS and the weather station and oven-drying method}

Fig. 4 shows the temporal variation of SWC measured from the CRNS, the weather station and the point values of SWC measured by the oven-drying method and the rainfall during the 2015 growing season. Nearly all the SWC peak values of the two SWC series in mid- and late June, early July and mid-August corresponded to rainfall, and the low rainfall from mid- to late July corresponded to a continuous decrease in SWC.

The five weighted means for the oven-drying method were very similar to the SWC measured by the CRNS (Figs. 4 and 5). The root mean square error (RMSE) was $0.011 \mathrm{~m}^{3} \mathrm{~m}^{-3}$, the Nash-Sutcliffe coefficient was 0.989 and the coefficient of determination $\left(R^{2}\right)$ was 0.949 , which indicated that despite the decreasing SWC in mid- to late July and the increasing SWC in mid-August, the CRNS could accurately measure mean SWC, i.e. after reasonable corrections for the measured raw neutron density, SWC measured by the CRNS could represent the mean SWC of the support volume in this AME on the northern Tibetan Plateau.

The mean SWC at a depth of $20 \mathrm{~cm}$ from the weather station tended to vary consistently with the measurements from the CRNS, with similar peaks and troughs (Fig. 4). The SWC from the weather station was slightly higher than the SWC from the CRNS in June and early July. This unexpected phenomenon might be due to the variation of the vegetational coverage of the weather station. At other times, the SWC was nearly equal to the SWC from the CRNS.

\subsection{Comparison of SWC measured by the CRNS and the Em-50 instruments}

Mean SWC to a depth of $20 \mathrm{~cm}$ was similar in the 2012 and 2013 sub-quadrats throughout the whole growing season and was generally higher in the 2011 sub-quadrat (Fig. 6). The SWC measured by the CRNS decreased during the abnormal drought, similar to the SWCs measured by the 2012 and 2013 Em-50s, and the SWC measured by the CRNS was about 5\% lower than the 2011 Em-50 value. SWC remained relatively stable after midAugust, with similar CRNS and 2011 sub-quadrat values, but the SWCs from the CRNS were about 5\% higher than the values in the 2012 and 2013 sub-quadrats. The SWC from the CRNS was generally slightly lower in July and higher in August than the SWCs measured by the three Em-50 instruments. The Em- 50 missed several rains around 8 and 14 July that were captured by the cosmicray probe, perhaps because the potential evapotranspiration was high in July, and the rainfall was relatively low. Rain-water evaporated before it reached the Em-50 probes buried in the soil. In August, however, the Em-50 captured most of the rains, because the rainfalls were higher and the SWC was relatively high. SWC measured by the CRNS differed from the mean SWCs measured in the three sub-quadrats at some stages of the 2015 growing season, but the trends and some fluctuations of SWC generally corresponded.

\subsection{Daily fluctuations of SWC measured by the CRNS, the weather station and the Em-50 instruments}

The daily fluctuations of SWC measured by the CRNS, the weather station and the Em-50 instruments could be discriminated, especially during the dry period. Mean hourly SWC for 13 days measured by the three methods from 19 to 31 July, when no rain fell, indicated a daily variation of the SWC (Fig. 7). The diurnal variation of hourly SWC from the CRNS was sinusoidal (Fig. 7a),

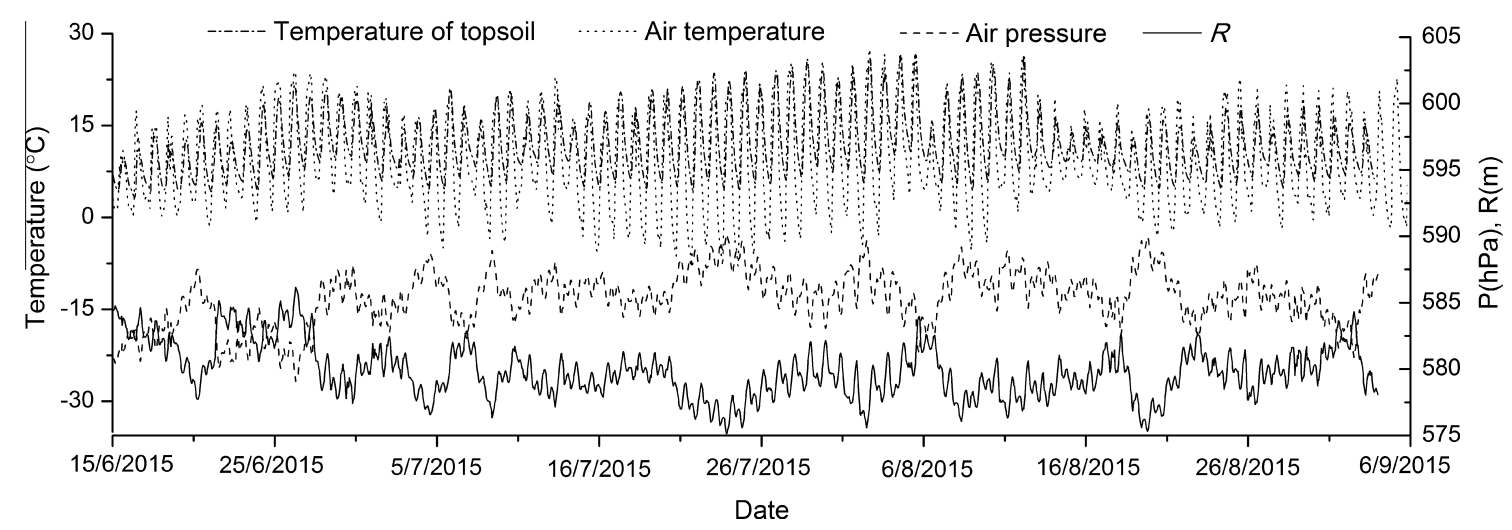

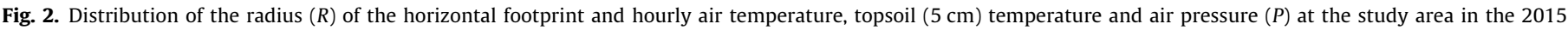
growing season. 


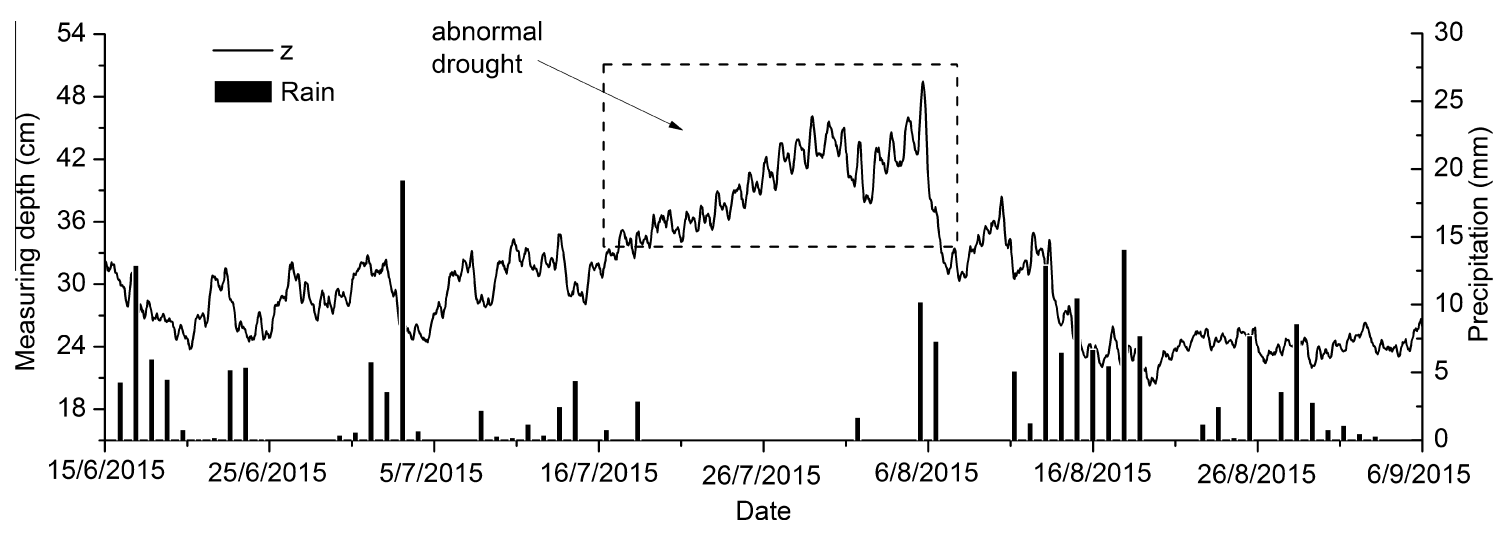

Fig. 3. Time series of measuring depth of the CRNS.

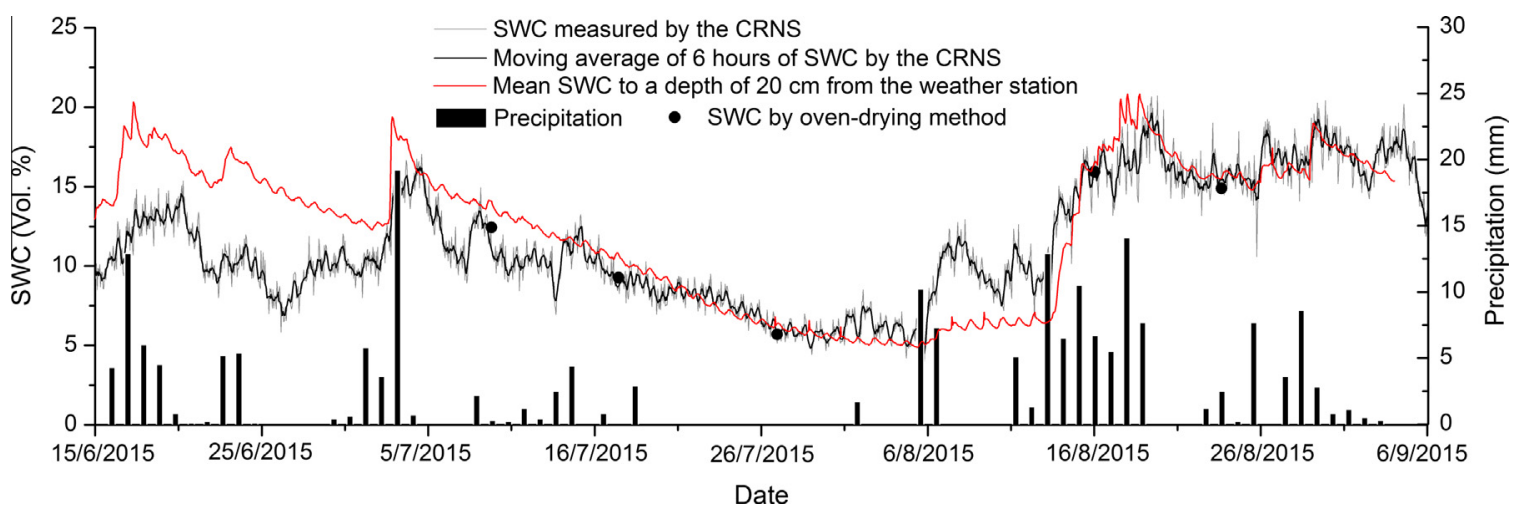

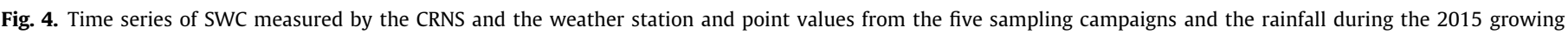
season.

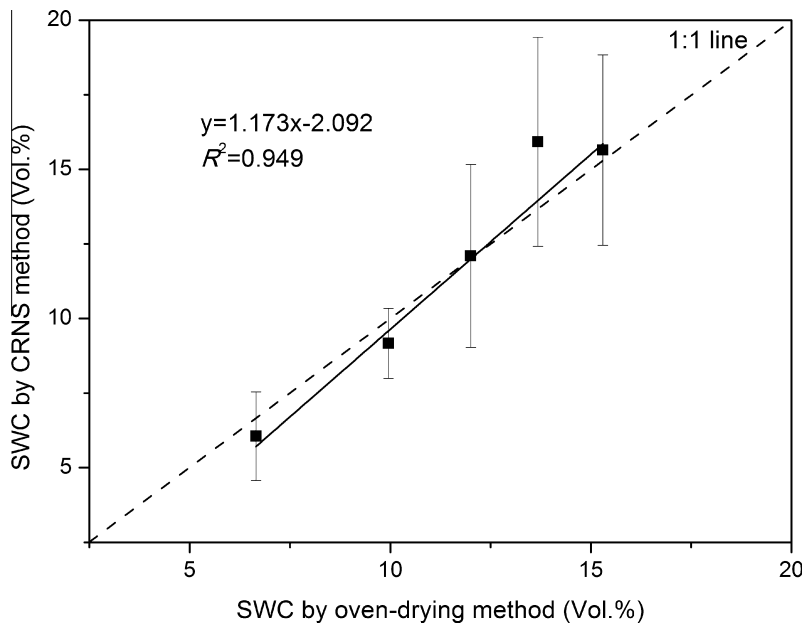

Fig. 5. Correlation between SWC measured by the CRNS and oven-drying methods. Vertical bars represent \pm one standard deviation.

peaking at 11:00 and was minimum at 18:00 (Beijing time), with a range of $1 \%$. The daily processes of the SWC from the weather station and the Em-50 instruments, however, showed a weak cosine variation (Fig. $7 \mathrm{~b}$ and c), both with ranges of $0.3 \%$. The standard deviations were similar for each hourly SWC, indicating that variations of the hourly SWC were similar from 19 to 31 July for each of the three methods.

\section{Discussion}

\subsection{Applicability of the CRNS for measuring SWC in high and cold areas}

The cosmic-ray SWC observation method was applicable in the AME on the northern Tibetan Plateau. The oven-drying method is considered the most direct method for measuring SWC and is often used to correct SWCs measured by indirect methods. In our study, the mean SWCs measured by the CRNS were nearly equal to those from the oven-drying method (Fig. 4), despite the abnormal drought in late July and the adequate rainfall in early August. The CRNS could thus accurately monitor the variation of mean SWC in this alpine ecosystem under both drought and humid conditions.

The trends of SWCs from the weather station and the Em-50s were basically consistent with the SWC trend from the CRNS. SWCS from the weather station were similar to that from the CRNS during most of the growing season except June, which may have been caused by the activities of the vegetation. The SWCs from the Em50s were either higher in July or lower in August compared to those from the CRNS. The data for the CRNS and the independent field samples agreed well, so this discrepancy may have been due to the different properties of the sub-quadrats. The three sub-quadrats were far from the CRNS and from each other (Fig. 1), the topographies and soil properties differed between the sub-quadrats. Also, the sub-quadrats were established at different times, so their mean vegetational coverages differed, with the order $2011(0.36)>2012(0.27)>2013(0.25)$. The representativeness of the field mean SWC for the three locations was thus insufficient. The trends and fluctuations of the SWCs from the three 


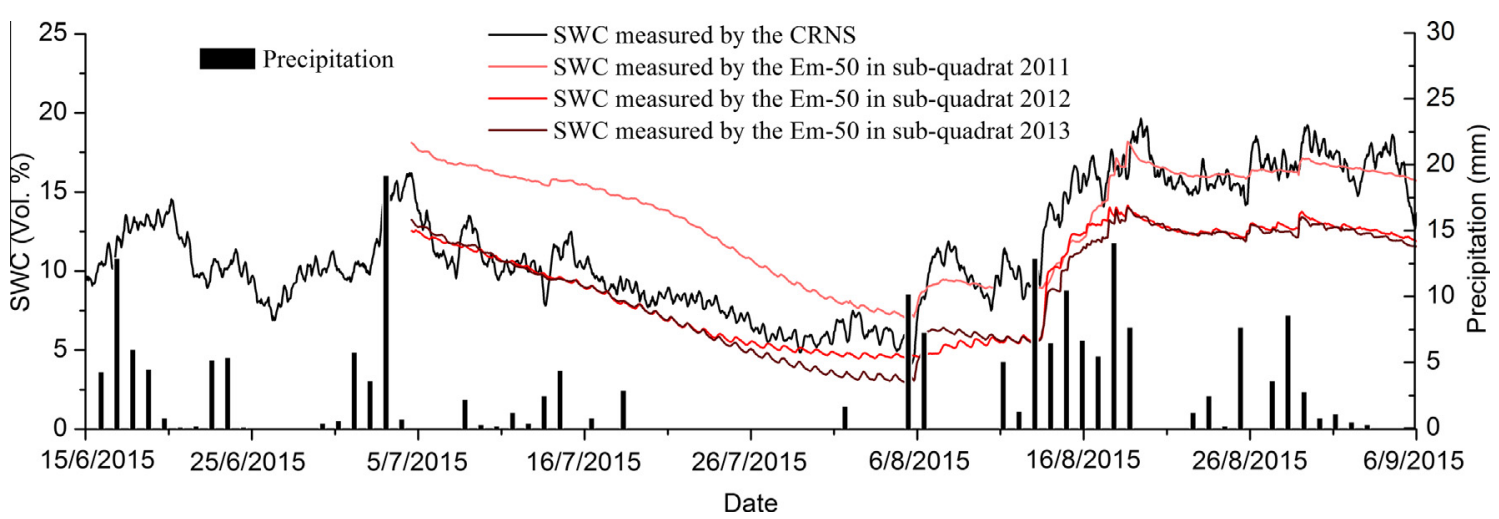

Fig. 6. Comparison of SWCS measured by the CRNS and the Em-50 instruments.
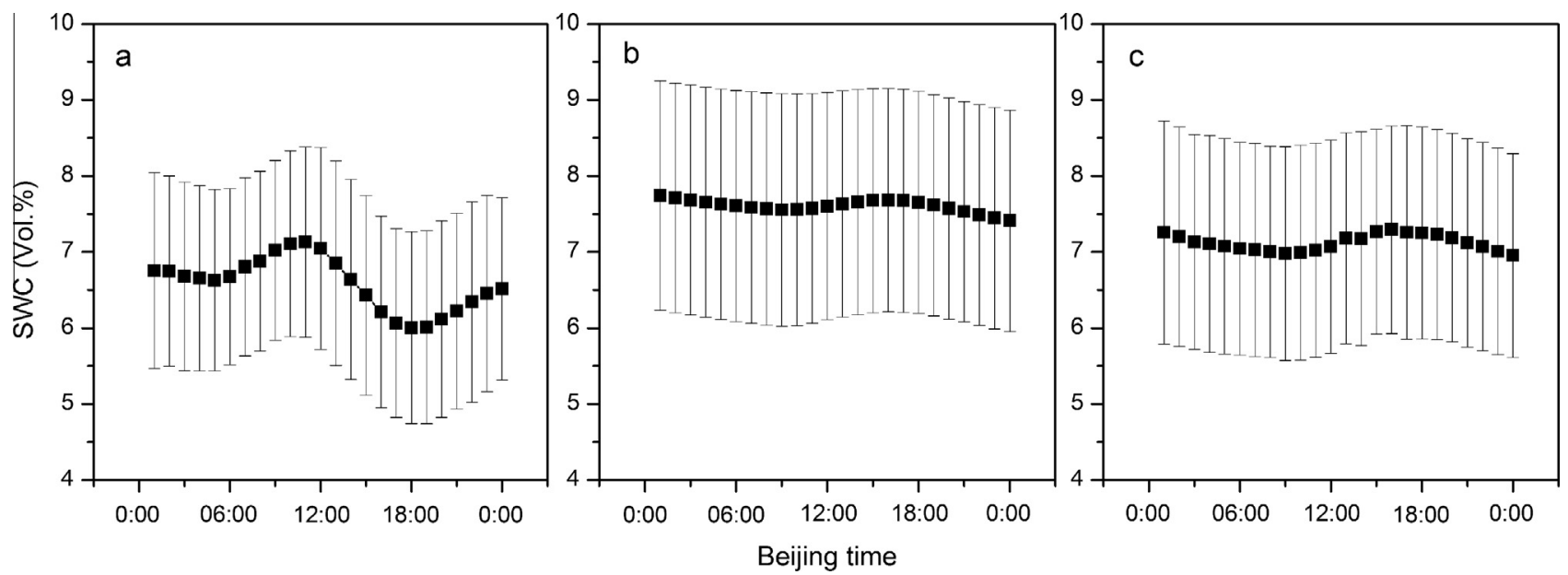

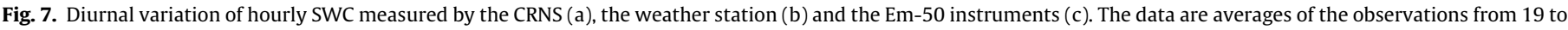
31 July when no rain fell (for (b and c), the data were mean SWC to a depth of $20 \mathrm{~cm}$ ). Vertical bars represent \pm one standard deviation.

Em-50s, however, were generally consistent with those that from the CRNS.

\subsection{Daily variation of the SWC measured by the CRNS}

Daily fluctuation of SWC in drought period was discernable, and the fluctuations perhaps be caused by dew on the surface ground. SWC inverted from the CRNS increased in the morning when the dew fell and decreased at noon and in the afternoon when the dew evaporated to the air or infiltrated into the soil (Fig. 7). The SWC increased again after 18:00 (Beijing time) when air temperature decreased. The specific influence of dew on the SWC in the dry period, however, was not clear and difficult to quantify. Daily fluctuations of the SWC measured by the CRNS have also been reported in another study (Baroni and Oswald, 2015), and researchers have been paying attentions on this phenomenon and the forming reasons. No specific conclusions have been drawn about the main determinants of the daily variation. The daily variation of the SWC measured by the CRNS requires further study and more field data.

\section{Conclusions}

Detecting cosmic-ray neutrons is a new method for measuring mean SWC at hectometer scales and can compensate for scales differences between conventional point measurements and remote sensing retrieval. It has the advantages of nonintrusive, continuous observation with high time resolution and represents a new approach for SWC studies. A cosmic-ray neutrons probe was installed in an AME on the northern Tibetan Plateau for measuring the mean SWC during the 2015 growing season. A nearby weather station also measured SWC at various soil depths. Three Em-50 instruments were buried at different places to measure the SWC and temperature at various soil depths. The footprint radius of the CRNS method was about $580 \mathrm{~m}$ and the measuring depth was about $31 \mathrm{~cm}$ in our study area based on the general calculation equations. The accuracy of the CRNS method was relatively high when validated against the oven-drying method. The RMSE was $0.011 \mathrm{~m}^{3} \mathrm{~m}^{-3}$, and the Nash-Sutcliffe coefficient was 0.989 . The mean SWCs measured at the weather station to a depth of $20 \mathrm{~cm}$ were consistent with the mean SWCs from the CRNS. The different micro-topographies, biomasses and soil properties in the three sub-quadrats led to some offsets of the mean SWCs measured by the three Em-50s. The diurnal variation of hourly SWCs from the CRNS was sinusoidal, with a range of $1 \%$. This study provides a scientific basis for the application of the CRNS for monitoring SWC in high and cold areas and represents a new approach for the study of SWC spatial distribution in AMEs on the Tibetan Plateau. Combining the CRNS with remote sensing for measuring and correcting SWC on a relatively large scale on the Tibetan Plateau will be a promising field.

\section{Acknowledgements}

The study was financially supported by the National Natural Science Foundation of China (Nos. 41230746 and 41401247). 
Jungfraujoch neutron monitor data were kindly provided by the Cosmic Ray Group, Physikalisches Institut, University of Bern, Switzerland. The authors are grateful to Dr. Desilets for helping to improve the manuscript and to the other two anonymous reviewers for their constructive comments and suggestions.

\section{References}

Baatz, R., Bogena, H.R., Hendricks Franssen, H.-J., Huisman, J.A., Qu, W., Montzka, C., Vereecken, H., 2014. Calibration of a catchment scale cosmic-ray probe network: a comparison of three parameterization methods. J. Hydrol. 516, 231-244. http://dx.doi.org/10.1016/j.jhydrol.2014.02.026.

Baatz, R., Bogena, H.R., Hendricks Franssen, H.-J., Huisman, J.A., Montzka, C., Vereecken, H., 2015. An empirical vegetation correction for soil water content quantification using cosmic ray probes. Water Resour. Res. 51 (4), 2030-2046. http://dx.doi.org/10.1002/2014WR016443.

Baroni, G., Oswald, S.E., 2015. A scaling approach for the assessment of biomass changes and rainfall interception using cosmic-ray neutron sensing. J. Hydrol. 525, 264-276. http://dx.doi.org/10.1016/j.jhydrol.2015.03.053.

Bogena, H.R., Huisman, J.A., Baatz, R., Hendricks Franssen, H.-J., Vereecken, H., 2013. Accuracy of the cosmic-ray soil water content probe in humid forest ecosystems: the worst case scenario. Water Resour. Res. 49 (9), 5778-5791. http://dx.doi.org/10.1002/WRCR.20463.

Coopersmith, E.J., Cosh, M.H., Daughtry, C.S.T., 2014. Field-scale moisture estimates using COSMOS sensors: a validation study with temporary networks and LeafArea-Indices. J. Hydrol. 519, 637-643. http://dx.doi.org/10.1016/j. jhydrol.2014.07.060.

Desilets, D., Zreda, M., 2001. On scaling cosmogenic nuclide production rates for altitude and latitude using cosmic-ray measurements. J. Hydrol. 193, 213-225. http://dx.doi.org/10.1016/S0012-821X(01)00477-0.

Desilets, D., Zreda, M., Ferré, T.P.A., 2010. Nature's neutron probe: land surface hydrology at an elusive scale with cosmic rays. Water Resour. Res. 46 (11). http://dx.doi.org/10.1029/2009WR008726.

Desilets, D., Zreda, M., 2013. Footprint diameter for a cosmic-ray soil moisture probe: theory and Monte Carlo simulations. Water Resour. Res. 49 (6), 35663575. http://dx.doi.org/10.1002/WRCR.20187.

Franz, T.E., Zreda, M., Ferré, T.P.A., Rosolem, R., Zweck, C., Stillman, S., Zeng, X., Shuttleworth, W.J., 2012. Measurement depth of the cosmic ray soil moisture probe affected by hydrogen from various sources. Water Resour. Res. 48 (8). http://dx.doi.org/10.1029/2012WR011871.

Franz, T.E., Zreda, M., Rosolem, R., Ferré, T.P.A., 2013. A universal calibration function for determination of soil moisture with cosmic-ray neutrons. Hydrol. Earth Syst. Sci. 17 (2), 453-460. http://dx.doi.org/10.5194/hess-17-453-2013.

Han, X.J., Jin, R., Li, X., Wang, S.G., 2014. Soil moisture estimation using cosmic-ray soil moisture sensing at heterogeneous farmland. IEEE Geosci. Remote Sens. Lett. 11 (9), 1659-1663. http://dx.doi.org/10.1109/LGRS.2014.2314535.

Han, X., Franssen, H.-J.H., Rosolem, R., Jin, R., Li, X., Vereecken, H., 2015. Correction of systematic model forcing bias of CLM using assimilation of cosmic-ray neutrons and land surface temperature: a study in the Heihe Catchment, China. Hydrol. Earth Syst. Sci. 19 (1), 615-629. http://dx.doi.org/10.5194/hess-19-615-2015.

Hawdon, A., McJannet, D., Wallace, J., 2014. Calibration and correction procedures for cosmic-ray neutron soil moisture probes located across Australia. Water Resour. Res. 50 (6), 5029-5043. http://dx.doi.org/10.1002/2013WR015138.
Jia, Y.H., Shao, M.A., 2013. Temporal stability of soil water storage under four types of revegetation on the northern Loess Plateau of China. Agr. Water Manage. 117, 33-42. http://dx.doi.org/10.1016/j.agwat.2012.10.013.

Köhli, M., Schrön, M., Zreda, M., Schmidt, U., Dietrich, P., Zacharias, S., 2015 Footprint characteristics revised for field-scale soil moisture monitoring with cosmic-ray neutrons. Water Resour. Res. 51 (7), 5772-5790. http://dx.doi.org/ 10.1002/2015WR017169.

Lv, L., Franz, T.E., Robinson, D.A., Jones, S.B., 2014. Measured and modeled soil moisture compared with cosmic-ray neutron probe estimates in a mixed forest. Vadose Zone J. 13 (12). http://dx.doi.org/10.2136/vzj2014.06.0077.

Mcjannet, D., Franz, T., Hawdon, A., Boadle, D., Baker, B., Almeida, A., Silberstein, R., Lambert, T., Desilets, D., 2014. Field testing of the universal calibration function for determination of soil moisture with cosmic-ray neutrons. Water Resour. Res. 50 (6), 5235-5248. http://dx.doi.org/10.1002/2014WR015513.

Moraal, H., Caballero-Lopez, R.A., McCracken, K.G., Humble, J.E., 2005. The influence of cosmic-ray modulation at high heliospheric latitudes on the solar diurnal variation observed at earth. Astrophys. J. 629, 556-560.

Rivera Villarreyes, C.A., Baroni, G., Oswald, S.E., 2011. Integral quantification of seasonal soil moisture changes in farmland by cosmic-ray neutrons. Hydrol. Earth Syst. Sci. 15 (12), 3843-3859. http://dx.doi.org/10.5194/hess-15-38432011.

Rosolem, R., Shuttleworth, W.J., Zreda, M., Franz, T.E., Zeng, X., Kurc, S.A., 2013. The effect of atmospheric water vapor on neutron count in the cosmic-ray soil moisture observing system. J. Hydrometeorol. 14 (5), 1659-1671. http://dx.doi. org/10.1175/jhm-d-12-0120.1.

Rosolem, R., Hoar, T., Arellano, A., Anderson, J.L., Shuttleworth, W.J., Zeng, X., Franz, T.E., 2014. Translating aboveground cosmic-ray neutron intensity to highfrequency soil moisture profiles at sub-kilometer scale. Hydrol. Earth Syst. Sci. 18 (11), 4363-4379. http://dx.doi.org/10.5194/hess-18-4363-2014.

Shuttleworth, J., Rosolem, R., Zreda, M., Franz, T., 2013. The COsmic-ray Soil Moisture Interaction Code (COSMIC) for use in data assimilation. Hydrol. Earth Syst. Sci. 17 (8), 3205-3217. http://dx.doi.org/10.5194/hess-17-3205-2013.

Vereecken, H., Huisman, J.A., Pachepsky, Y., Montzka, C., van der Kruk, J., Bogena, H., Weihermüller, L., Herbst, M., Martinez, G., Vanderborght, J., 2014. On the spatiotemporal dynamics of soil moisture at the field scale. J. Hydrol. 516, 76-96. http://dx.doi.org/10.1016/j.jhydrol.2013.11.061.

Wang, Q.M., Wang, S., Fan, J., 2015. Application of cosmic-ray fast neutron method to measure soil moisture: A case study of Liudaogou basin in Shaanxi. Sci. Soil Water Conserv. 13 (5), 125-131. http://dx.doi.org/10.3969/j.issn.1672 3007.2015.05.019 (in Chinese).

Zhu, Z.L., Tan, L., Gao, S.G., Jiao, Q.S., 2015. Observation on soil moisture of irrigation cropland by cosmic-ray probe. IEEE Geosci. Remote Sens. Lett. 12 (3), 472-476. http://dx.doi.org/10.1109/lgrs.2014.2346784.

Zreda, M., Desilets, D., Ferré, T.P.A., Scott, R.L., 2008. Measuring soil moisture content non-invasively at intermediate spatial scale using cosmic-ray neutrons. Geophys. Res. Lett. 35 (21). http://dx.doi.org/10.1029/2008GL035655.

Zreda, M., Shuttleworth, W.J., Zeng, C., Desilets, D., Franz, T., Rosolem, R., 2012. COSMOS: the COsmic-ray Soil Moisture Observing System. Hydrol. Earth Syst. Sci. 16 (11), 4079-4099. http://dx.doi.org/10.5194/hess-16-4079-2012.

Zhao, C., Yuan, G.F., Liu, X., Shao, M.A., Yi, X.B., 2015. Application of comic-ray method to soil moisture measurement of grassland in the Loess Plateau. Acta Pedol. Sin. 52 (6), 1438-1444. http://dx.doi.org/10.11766/trxb201503110122 (in Chinese). 